\title{
A SIMULATION MODEL FOR ESTIMATING HUMAN ERROR PROBABILITY
}

\author{
Anastasia Angelopoulou ${ }^{(a)}$, Konstantinos Mykoniatis ${ }^{(b)}$, Nithisha Reddy Boyapati ${ }^{(c)}$ \\ (a),(c) Columbus State University \\ (b) Auburn University \\ (a) angelopoulou_anastasia@columbusstate.edu, ${ }^{(b)}$ kmykoniatis@ gmail.com, \\ (c) boyapati_nithishareddy@columbusstate.edu
}

\begin{abstract}
This paper describes the system dynamics architecture of a simulation model which estimates human error probability for humans performing certain tasks in a given scenario. Human error probability is estimated as a function of the type of tasks performed and the number of performance shaping factors. In this work, the Standardized Plant Analysis Risk-Human (SPAR-H) reliability analysis method is utilized for estimating the probability of human error. The system dynamics simulation model captures the cause and effect relationships of the SPAR-H defined performance shaping factors that affect human error and uses them to assess the overall human error probability of the system. The present work is a continuation of our previous work on task analysis, workload and human reliability assessment simulation and aims to evaluate the system dynamics simulation as a potential approach to assess human reliability.
\end{abstract}

Keywords: Simulation; Modeling; System Dynamics; Human Error

\section{INTRODUCTION}

Human error is one of the main contributing factors in accidents and disasters in various industries and accounts for more than $90 \%$ in nuclear industries and $80 \%$ in chemical industries (Ramondo et al. 2012). Human error is also one of the primary causes of some of the most shocking industrial accidents that occurred around the world such as the Texaco refinery accident in Wales (1994), the Chernobyl nuclear disaster in Ukraine (1986), the Piper Alpha accident in United Kingdom (1988) and the Bhopal gas disaster in India (1984) (Johnson 1999). Therefore, human error prevention is seen as a major contribution to the safety, maintenance, and reliability of systems.

Modeling and Simulation (M\&S) is a tool that can address the dynamic nature and progression of human behavior and provides a way to estimate and/or predict the human error probability (HEP) when humans perform tasks. Estimating or predicting the HEP can help determine policies to be applied in order to avoid errors and/or reduce the likelihood of errors, especially if the tasks are critical. Policies may include but are not limited to adding more operators to perform certain tasks and manage critical constraints; reconfiguring the layout and/or testing alternative working environments; training the operator to improve his/her skills for critical tasks; applying risk-based planning and scheduling (i.e. by changing shifts or taking a break before starting a certain task).

M\&S has been used in the past to analyze human behavior in order to assess human reliability. Different models and simulation paradigms have been used for human reliability assessment. More specifically, Discrete Event Simulation (DES) has been utilized to model human behavior and to predict the error probability for given scenarios (Di Pasquale et al. 2015), as well as to improve a production process considering the availability and reliability of machines, operators, and robots as stochastic parameters (Kampa et al. 2017). Agent Based (AB) simulation models have focused on evaluating human performance and behavior (Deadman 1999; Pritchett et al. 2002; Bonabeau 2002). Bayesian Belief Network (Belkacem et al. 2011; Gregoriades 2018) and Petri-nets have also application in safety, reliability, and risk assessments (Kabi and Papadopoulos 2019). Finally, System Dynamics (SD) simulation models have been utilized as a tool to assess human performance and human reliability (Block and Pickl 2014; Angelopoulou 2015; Angelopoulou and Mykoniatis 2017; Gregoriades 2018).

The current paper focuses on the description of the SD module of a "work-in-progress" hybrid simulation model for the estimation of HEP by utilizing the SPAR$\mathrm{H}$ method's Performance Shaping Factors (PSFs). The model is a continuation of our previous work (Angelopoulou 2015; Mykoniatis 2015; Angelopoulou and Mykoniatis 2017; Angelopoulou and Mykoniatis 2018; Mykoniatis and Angelopoulou 2019).

The remainder of the paper is organized as follows: Section 2 provides an overview of the SPAR-H human reliability assessment method and the defined PSFs, while Section 3 describes the SD architecture of our hybrid AB-SD model and the cause and effect relationships of the SD model components. Finally, in Section 4 we discuss conclusions and future work.

\section{HUMAN RELIABILITY ASSESSMENT}

A hybrid AB-SD simulation model has been developed for estimating the human error probability (HEP). In 
this work, the SPAR-H method is utilized as a basis to build the SD module of the hybrid model for estimating the HEP of the system. The SPAR-H method (Boring and Blackman 2007; US Nuclear Regulatory Commission 2005) was developed for assessing human error probabilities in the nuclear industry but shows promise for wider application in other domains (Boring and Gertman 2005; Bell and Holroyd 2009). The SPAR-H method utilizes eight PSFs: Available Time, Stress, Complexity, Experience, Procedure, Ergonomics, Fitness for Duty, and Work processes.

Each PSF has different levels and each level is associated with a multiplier that increases or decreases the likelihood of errors. For example, a high multiplier (greater than 1) increases the likelihood of human error and a low multiplier (less than 1) decreases it. The list of the multiplier scale used in the SD model for the HEP estimation is presented in Table 1.

Table 1

PSF Multipliers used in the system dynamics model for the HEP estimation (Boring and Blackman 2007)

\begin{tabular}{|c|c|c|}
\hline PSF & PSF Level & Multiplier \\
\hline \multirow{4}{*}{ Available Time } & Inadequate time & No multiplier \\
\hline & Barely Adequate time & 10 \\
\hline & Nominal Time & 1 \\
\hline & Extra Time & 0.1 \\
\hline \multirow{3}{*}{ Stress } & Extreme & 5 \\
\hline & High & 2 \\
\hline & Nominal & 1 \\
\hline \multirow{4}{*}{ Complexity } & High & 5 \\
\hline & Moderate & 2 \\
\hline & Nominal & 1 \\
\hline & Obvious & 0.1 \\
\hline \multirow{3}{*}{ Experience } & Low & 10 \\
\hline & Nominal & 1 \\
\hline & High & 0.5 \\
\hline \multirow{5}{*}{ Procedures } & Not available & 50 \\
\hline & Incomplete & 20 \\
\hline & Poor & 5 \\
\hline & Nominal & 1 \\
\hline & Good & 0.5 \\
\hline \multirow{3}{*}{ Work process } & Poor & 2 \\
\hline & Nominal & 1 \\
\hline & Good & 0.8 \\
\hline \multirow{4}{*}{ Ergonomics } & Missing & 50 \\
\hline & Poor & 10 \\
\hline & Nominal & 1 \\
\hline & Good & 0.5 \\
\hline \multirow{3}{*}{ Fitness for Duty } & Unfit & No multiplier \\
\hline & Degraded & 5 \\
\hline & Nominal & 1 \\
\hline
\end{tabular}

If there is no information available in order to provide a judgment for the PSF level, the PSF level is assumed to be nominal (equal to 1). Once the levels of each PSF are assigned, the final HEP is estimated as the product of the PSF multipliers and the base error rate, as in (1).

$$
\begin{aligned}
& H E P=N H E P \times P S F C \\
& P S F C=\pi P S F S
\end{aligned}
$$

The base error rate or nominal human error probability (NHEP) is equal to 0.001 for action tasks and 0.01 for diagnosis tasks.

PSFs may increase, decrease or have no effect on human error probability. If three or more PSFs have a negative effect on HEP, a correction process of SPAR$\mathrm{H}$ is applied, as in (2).

$$
H E P=\frac{N H E P \times P S F C}{N H E P(P S F C-1)+1}
$$

This HEP provides a quantitative basis to the system's evaluation. Based on the HEP, each task will be further classified as critical or not in order to aid analysts in determining which areas of the system may need redesign or caution.

\section{SYSTEM DYNAMICS SIMULATION MODEL}

The hybrid AB-SD model consists of agents that represent the human operators performing a task. A SD model is incorporated within each agent in order to estimate the probability that each individual will make an error while performing a task. The model presented in this paper discusses the SD module of the hybrid simulation model.

The simulation model is developed in Anylogic ${ }^{\mathrm{TM}}$, reads inputs from a database and estimates the probability of the errors to occur based on the type of the task (action vs. diagnosis task) and the performance shaping factors. The SD model is depicted in Figure 1 and the model variables are presented in Table 2 . Subsection 3.1 describes the SD model variables in more detail, while subsection 3.2 focuses on the description of the causal loops and the HEP correction process.

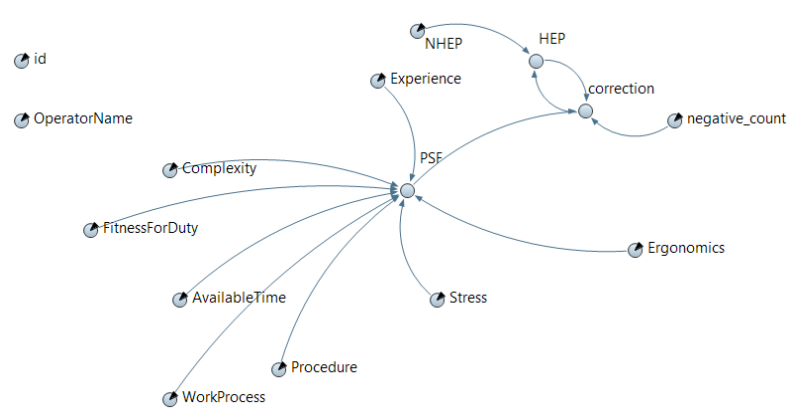

Figure 1: System Dynamics Model 
Table 2

Description of System Dynamics Model Variables

\begin{tabular}{|l|l|l|}
\hline Properties & Definition & Model Variable \\
\hline ID & Unique identifier & id (integer) \\
\hline $\begin{array}{l}\text { Operator } \\
\text { Name }\end{array}$ & $\begin{array}{l}\text { The name of the operator } \\
\text { performing the task }\end{array}$ & $\begin{array}{l}\text { OperatorName } \\
\text { (String) }\end{array}$ \\
\hline $\begin{array}{l}\text { Available } \\
\text { Time }\end{array}$ & $\begin{array}{l}\text { The time for which an operator } \\
\text { will be available for } \\
\text { performing the task. }\end{array}$ & $\begin{array}{l}\text { AvailableTime } \\
\text { (double) }\end{array}$ \\
\hline Stress & $\begin{array}{l}\text { Stress levels of an operator } \\
\text { during the task performance. }\end{array}$ & Stress (double) \\
\hline Complexity & $\begin{array}{l}\text { States the complexity of a task } \\
\text { to be performed. }\end{array}$ & $\begin{array}{l}\text { Complexity } \\
\text { (double) }\end{array}$ \\
\hline Experience & $\begin{array}{l}\text { Experience level of each } \\
\text { operator while performing the } \\
\text { task. }\end{array}$ & $\begin{array}{l}\text { Experience } \\
\text { (double) }\end{array}$ \\
\hline Procedure & $\begin{array}{l}\text { Describes the knowledge of an } \\
\text { operator on a specific task. }\end{array}$ & $\begin{array}{l}\text { Procedure } \\
\text { (double) }\end{array}$ \\
\hline Ergonomics & $\begin{array}{l}\text { States the efficiency of an } \\
\text { operator while performing the } \\
\text { task. }\end{array}$ & $\begin{array}{l}\text { Ergonomics } \\
\text { (double) }\end{array}$ \\
\hline $\begin{array}{l}\text { Fitness for } \\
\text { Duty }\end{array}$ & $\begin{array}{l}\text { Fitness level of an operator } \\
\text { during the task performance. }\end{array}$ & $\begin{array}{l}\text { FitnessForDuty } \\
\text { (double) }\end{array}$ \\
\hline $\begin{array}{l}\text { Work } \\
\text { processes }\end{array}$ & $\begin{array}{l}\text { States the process of work of } \\
\text { an operator }\end{array}$ & $\begin{array}{l}\text { WorkProcesses } \\
\text { (double) }\end{array}$ \\
\hline NHEP & $\begin{array}{l}\text { Nominal Human Error } \\
\text { Probability whose values are } \\
\text { 0.01 and 0.001 }\end{array}$ & NHEP(double) \\
\hline Hegative \\
Hount & $\begin{array}{l}\text { Human Error Probability } \\
\text { founts the number of negative } \\
\text { HEP correction. }\end{array}$ & $\begin{array}{l}\text { negative_count } \\
\text { (integer) } \\
\text { when there are 3 or more }\end{array}$ \\
\hline Correction & $\begin{array}{l}\text { Applies the HEP correction } \\
\text { (double) }\end{array}$ \\
\hline
\end{tabular}

\subsection{System Dynamics Model Variables}

A unique identifier (ID) is assigned to each simulated agent upon creation. The model then reads the database inputs and assigns the operator name to each agent, as well as values to each of the PSF factors.

The available time is generally referred to as the amount of time that a crew or an operator must act and diagnose upon an abnormal event (Gertman et al. 2005; Boring and Blackman 2007; Blackman, Gertman and Boring 2008; Whaley et al. 2012). In the SD model, the PSF "AvailableTime" denotes the amount of time available for the task relative to the time that is required to complete a task. The HEP and the availability of the worker during the time of performing the tasks are inversely proportional to each other. In other words, if the worker is unavailable to perform an operation, the probability that he/she might commit an error will be high and approximately 1 . The HEP will be reduced if the worker is available most of the time to perform the task, even during an emergency.

In the SPAR-H context, stress refers to the level of undesirable circumstances and conditions that impede an operator to complete the task (Gertman et al. 2005; Boring and Blackman 2007; Blackman, Gertman and Boring 2008; Whaley et al. 2012). The effect of stress on the performance is curvilinear, which indicates that even small amounts of stress can improve the performance and consider it as nominal, while extreme and high stress levels may affect the human performance in a negative way. The HEP is assumed to be approximately 1 if the worker's stress levels are high before or at the time of performing a task.

The complexity refers to the difficulty of the task to be performed in a certain context considering both the environment and the task (Gertman et al. 2005; Boring and Blackman 2007; Blackman, Gertman and Boring 2008; Whaley et al. 2012). As the complexity of the task increases, the probability of human error will also increase since they are directly proportional to each other. At the same time a more ambiguous task may have a higher chance for human error. Boring, Griffith and Joe (2007) defined complexity as indirect as it cannot be directly measured. Due to this reason, the complexity value cannot be directly assigned but it depends on the input factor from various elements such as parallel tasks general complexity, need for mental errors, physical effort needed from the activity type and the level of precision for the activity. These elements will be incorporated in the model in the future.

The experience refers to the operator's experience involved in a task (Gertman et al. 2005; Boring and Blackman 2007; Blackman, Gertman and Boring 2008; Whaley et al. 2012). The experience level is defined based on the operator's years of experience, whether the operator has been trained or not on the type of accident, the amount of time spent on the training and its frequency, involvement of system in the scenario and task. The three levels of the "Experience" variable are defined as follows:

- High: Demonstrated master; extensively experienced.

- Nominal: More than 6 months of training or/and experience.

- Low: Less than 6 months of training or/and experience.

More experienced workers present reduced probability to commit an error. If the worker has less or no experience then the probability of the worker to commit an error will be extremely high. As Duffey and Saull (2004) state: "Human error probability is dynamic and evolves with experience".

For the tasks under consideration, procedure refers to the use and existence of formal operating procedures (Gertman et al. 2005; Boring and Blackman 2007; Blackman, Gertman and Boring 2008; Whaley et al. 2012). Most common problems in event investigations of procedures involve situations where inadequate or wrong data are provided regarding a certain sequence of control. Ambiguity of steps is seen as another common problem. The HEP will be reduced if the worker uses and follows the existence of operating procedures while performing the task. Therefore, the HEP and the procedure to be followed by the worker during the time of performing the tasks are inversely proportional to each other. In other words, if the worker does not follow 
the procedure during the performance of an operation, the HEP will be high and approximately 1 .

Ergonomics refer to the interaction of the operator/crew with the equipment in carrying out the tasks, to the layout, equipment, controls and displays, as well as to the quality and quantity of available information from the instrumentation (Gertman et al. 2005; Boring and Blackman 2007; Blackman, Gertman and Boring 2008; Whaley et al. 2012). Human machine interface aspects as well as inadequacy or adequacy of the computer software are involved in this category. The HEP will be reduced if the operator has prior knowledge on the usage of the tools and equipment before performing the task. Therefore, there is an inversely proportional relationship between HEP and ergonomics. For example, if the operator/crew has no knowledge on the instrumentation information before performing an operation, the probability that he/she might commit a mistake will be extremely high.

Fitness for duty refers to whether the individual/crew is mentally and physically fit to perform the task or not (Gertman et al. 2005; Boring and Blackman 2007; Blackman, Gertman and Boring 2008; Whaley et al. 2012). This includes legal or illegal usage of drugs, distractions, personal problems, sickness, overconfidence, and fatigue, and contains factors that are associated with the individuals, but are not related to experience, training or stress. The levels for the "Fitness for duty" variable are defined as follows:

- Nominal: Individual can perform tasks; It should be used when the judgment is made by the analyst for the PSF and not as a performance driver.

- Degraded fitness: Even though performance is affected negatively, the individual can perform the tasks. For example, if an individual is sick, physical and mental performance will be affected. If individuals are inappropriately overconfident in their abilities to a task, they may exhibit degraded performance.

- Unfit: Individual cannot perform the tasks due to physical or mental incapacitation or other illness.

The HEP and fitness for duty are inversely proportional to each other. For example, if a worker is unfit to perform an operation, the probability that he/she might commit a mistake will be high and approximately 1 .

Finally, work processes refer to the work aspects such as work planning, safety culture, communication and management support, inter-organizational factors and policies (Gertman et al. 2005; Boring and Blackman 2007; Blackman, Gertman and Boring 2008; Whaley et al. 2012). The individual and crew performance can be affected based on how the work is planned, communicated and executed. If the communication and planning are poor, an individual may not understand the requirement of the work, which will lead to an increase in HEP. The HEP will be high if the operator/crew is not aware of how the work is planned, communicated and executed before performing an operation. This indicates that the HEP and work processes are indirectly proportional to each other. In other words, if an operator has no knowledge on the requirements of the work to be done prior to performing an operation, the probability that the worker might commit a mistake will be very high.

\subsection{Causal Loops}

The SD model is composed of causal loops that show the interrelations among the parameters/variables and expose feedback loops within the system. Causal loops are developed by correlating pairs of variables where one is dependent and the other independent.

A causal loop diagram is defined as the simple map of interactions along with all its constituent components of a system. The diagram consists of a set of edges and nodes. Edges are the links that define a relation or a connection between two variables, while nodes define the variables. The polarity of the edges or causal links is indicated by "+" for a positive link or "_" for a negative link. A positive link indicates that the two nodes are directly proportional to each other or change in the same direction, i.e. if the link in one node increases, the other node will also increase. A negative link indicates that the two nodes are inversely proportional to each other or change in the opposite direction i.e. if the link in one node increases, the other node will decrease.

A causal loop diagram reveals the system structure by capturing the consequent feedback loops interactions. Causal loops can be categorized as reinforcing or balancing. Reinforcing loops reinforce and influence the same state or action thus resulting in growth or decline. Balancing loops compare the actual state to the goal and then initiate a corrective action in response to the discrepancy between the two. In our model, a balancing loop is present (Figure 2).

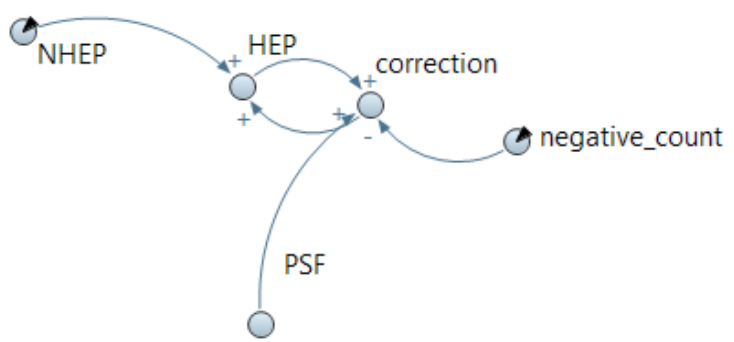

Figure 2. Balancing causal loop for applying the HEP correction. The number of negative links is odd.

The balancing loop affects the human error probability: If the number of negative PSFs increases to three or more (negative_count $\geq 3$ ), a correction is initiated to correct the HEP, if it is not within the appropriate range $(0 \leq \mathrm{HEP} \leq 1)$. In this paper, the HEP is the product of NHEP and the correction value. If the correction value increases, the value of HEP also increases and vice versa. The correction value is calculated based on the following condition: if three or more PSFs have a 
negative impact to HEP (negative_count $\geq 3$ ), then the value of PSFs is adjusted according to the correction formula (3). The correction formula ensures that the final individual HEP will not exceed the probability limit of 1 .

$$
\frac{\text { PSF }}{(\mathrm{PSF}-1)+\frac{1}{\mathrm{NHEP}}}
$$

\section{DISCUSSION AND FUTURE WORK}

This paper presented the components of a SD model for estimating human error probability when performing specific tasks in a given scenario. The simulation model takes as input the eight PSFs and the type of the task (NHEP) and outputs the estimation of the HEP for the total task and the HEP for each subtask. The factors that affect human error (PSFs) as well as the cause-effect relationships and feedback loops were also presented.

Future work will consist of the model validation using real-world case studies and will be compared with other HRA methods for accuracy. The model will be further developed to include more factors that affect human error and to provide suggestions that will decrease the likelihood of errors for the tasks with the higher error probabilities. An interface will also be created to allow the user to experiment with and compare alternative scenarios.

\section{REFERENCES}

Angelopoulou A., 2015. A Simulation-Based Task Analysis Using Agent-Based, Discrete Event and System Dynamics Simulation. Ph.D. Dissertation. University of Central Florida, Orlando, FL.

Angelopoulou A. and Mykoniatis K., 2017. The system dynamics architecture of UTASiMo: a simulationbased task analysis tool to predict human error probability. 2017 IEEE conference on cognitive and computational aspects of situation management (CogSIMA). Savannah, GA, USA, 27-31.

Angelopoulou A. and Mykoniatis K., 2018. UTASiMo: a simulation-based tool for task analysis. In: Simulation, 94(1), 43-54.

Belkacem O, Yang Z, Rochdi M, Wang J, 2011. Bayesian modelling for human error probability analysis in CREAM. Proceedings for the international conference on quality, reliability, risk, maintenance, and safety engineering. Xi'an, China. June 17-19.

Bell J. and J. Holroyd, 2009. Review of human reliability assessment methods. Health \& Safety Laboratory.

Blackman H. S., Gertman D. I., and Boring R. L., 2008. Human error quantification using performance shaping factors in the SPAR-H method. In: Proceedings of the human factors and ergonomics society annual meeting, 52(21), 17331737.
Block J. and Pickl S., 2014. The mystery of job performance: a system dynamics model of human behavior. Proceedings of the 32nd international conference of the System Dynamics Society, Delft, Netherlands, 20-24.

Bonabeau E., 2002. Agent-based modeling: Methods and techniques for simulating human systems. Proceedings of the national academy of sciences, 99 (suppl 3), 7280-7287.

Boring R. L., and Blackman H. S., 2007. The origins of the SPAR-H method's performance shaping factor multipliers. In: 2007 IEEE 8th Human Factors and Power Plants and HPRCT 13th Annual Meeting, 177-184.

Boring R. L. and Gertman D. I., 2005. Advancing Usability Evaluation through Human Reliability Analysis. Proceedings of HCI International.

Boring R. L., Griffith C. D., and Joe J. C., 2007. The measure of human error: Direct and indirect performance shaping factors. In 2007 IEEE 8th Human Factors and Power Plants and HPRCT 13th Annual Meeting, 170-176.

Deadman, P. J., 1999. Modelling individual behaviour and group performance in an intelligent agentbased simulation of the tragedy of the commons. Journal of Environmental Management, 56(3), 159-172.

Di Pasquale V., Miranda S., Iannone R., and Riemma S., 2015. A simulator for human error probability analysis (SHERPA). Reliability Engineering \& System Safety, 139, 17-32.

Duffey R. B. and Saull J. W., 2004. The probability and management of human error. In Proc. 12th Int. Conf. Nucl. Engineering (ICONE12), 3, 133-137.

Gertman D., Blackman H., Marble J., Byers J., and Smith C., 2005. The SPAR-H human reliability analysis method. US Nuclear Regulatory Commission, 230.

Gregoriades A., 2008. Human error assessment in complex socio-technical systems-system dynamic versus Bayesian belief network. In System Dynamics Conference, Manchester.

Johnson C, 1999. Why human error modeling has failed to help systems development. Interact Comput.

Kabir S., and Papadopoulos Y., 2019. Applications of Bayesian networks and Petri nets in safety, reliability, and risk assessments: A review. Safety science, 115, 154-175.

Kampa A., Gołda G., Paprocka I., 2017. Discrete event simulation method as a tool for improvement of manufacturing systems. Computers, 6(1), 10.

Mykoniatis K., 2015. A Generic Framework For MultiMethod Modeling and Simulation of Complex Systems Using Discrete Event, System Dynamics and Agent Based Approaches. Ph.D. Dissertation. University of Central Florida, Orlando, FL.

Mykoniatis K., and Angelopoulou A., 2019. A modeling framework for the application of multiparadigm simulation methods. SIMULATION, in press. 
Ramondo A, De Felice F, Carlomusto A, Petrillo A., 2012. Human reliability analysis: a review of the state of the art. IRACST - Int J Res Manage Technol (IJRMT) 2, 35-41.

Pritchett A. R., Lee S., Abkin M., Gilgur A. Z., Bea R. C., Corker K. M., ... and Jadhav, A., 2002. Examining air transportation safety issues through agent-based simulation incorporating human performance models. In: The 21st Digital Avionics Systems Conference, 2, 7A5-7A5.

US Nuclear Regulatory Commission, 2005. The SPAR-H human reliability analysis method.

Whaley A. M., Kelly D. L., Boring R. L., and Galyean W. J., 2012. SPAR-H step-by-step guidance (No. INL/CON-12-24693). Idaho National Laboratory (INL). 